\title{
Words for pharma: a quantitative and qualitative analysis on vision, mission and values of multinational pharmaceutical companies
}

\author{
Giulio Zuanetti ${ }^{1}$, Francesca Giorgia Colombo ${ }^{2}$, Carlotta Galeone ${ }^{3}$ \\ ${ }^{1}$ Aboutpharma HPS S.r.I., Milano - Italy \\ ${ }^{2}$ PharmD Student, Faculty of Pharmacy, Università Statale di Milano, Milano - Italy \\ ${ }^{3}$ Department of Clinical Sciences and Community Health, Università Statale di Milano, Milano - Italy
}

\begin{abstract}
Introduction: Pharma companies deal with the same important challenges that humans face: to grow and stay healthy. The crucial role of pharma companies in preserving health would suggest that they might rank highly in the reputation indexes. However, this does not seem to be the case. Our aim was to collect, cluster and analyse the words used by pharma companies in their mission, vision and value statements as a base to identify areas of improvement in their corporate communication.

Methods: A total of 97 multinational pharma companies were selected based on their size and presence within major markets. Mission, vision and company values were captured from company websites and analysed. Word clouds were built to analyse the frequency of words in the statement. The influence of company size and location was also analysed.

Results: Most companies (90.7\%) have a mission and $54.6 \%$ have a clearly stated vision statement, $71.4 \%$ mention values. "Life/lives" "patients", "innovative", "people/persons" are the most frequently used words. "Innovation" and "integrity" are by far the most common values, followed by "respect", "ethics", "responsibility" and "passion". References to healthcare professionals, access to treatment and sustainability, open science, transparency and care for the environment are more scanty.

Conclusions: Most, but not all, pharma companies provide comprehensive statements focussing mostly on the innovation and its impact on patients. Topics such as role of health care professionals, economic sustainability and care for the environment are rarely listed. An in-depth analysis of their alignment with key needs and trending topics is warranted to further engage customers and build reputation and value.
\end{abstract}

Keywords: Company mission, Company values, Pharma companies, Web reputation

\section{Introduction}

Pharmaceutical companies deal with what is perhaps the same important challenges that humans face in their lifetime: healthy growth, maintaining health and, if an acute or chronic disease occurs, to recover as quickly as possible and/or prevent complications from those diseases.

In order to meet these challenges, pharma companies face a rather unique industry and market scenario. In fact,

Received: March 2, 2020

Accepted: March 26, 2020

Published online: April 30, 2020

\section{Corresponding author}

Giulio Zuanetti, MD

Chairman

Aboutpharma HPS S.r.l.

Piazza Duca d'Aosta 12

20124 Milano, Italy

giulio.zuanetti@aboutpharma.com their business depends upon their research and development (R\&D) programme, including the careful testing of their drugs in clinical trials, the submission of registration dossiers to regulatory agencies for approval and the timely engagement of their direct customers (i.e. the physicians, the pharmacists, the regulators and the payors) to secure a rapid and effective market access. Yet, none of these stakeholders is the final user, that is, the individual patient, who benefits from drug treatment together with his/her family members and/ or caregivers.

The crucial role of pharma companies in preserving health would suggest that they might rank highly in the reputation indexes. However, this does not seem to be the case $(1,2)$.

Corporations in different business environments use specific wording to communicate their philosophy and their brand identity: commonly, but not always, they articulate the company vision, the company mission and the company values (3) and sometimes they summarize them by adding a short tagline to their brand. 
The main purpose of our study was to collect, cluster and analyse the words used by pharma companies in their corporate statements, in order to identify common themes (such as innovation, patient centricity, breadth of offering, operational excellence, outcome, trust) and to identify the words used most frequently by pharma companies worldwide. This might help to identify which themes could be useful to better familiarize customers, improve pharma company reputation and, ultimately, their business value.

\section{Methods}

The initial selection of companies was based on their size and market share. We identified the top 50 global companies, based on the rankingthebrand report (4). In addition, we identified a convenience sample of an additional 48 multinationals selected according to where their headquarters (HQ) were based in the most important pharma markets in Europe (UK, Germany, France, Italy, Spain and Portugal). The identification and the final selection were based on desktop research, as well as on suggestions by expert colleagues in those countries. Names of individuals are listed in the acknowledgement section.

Finally, we applied the predetermined exclusion criteria to exclude the suggested companies which appeared to be active only in one country and/or did not have an Englishlanguage corporate website. The corporate websites were searched to identify and list the following statements: mission, vision and company values. Specific URLs for each company analysed are listed in Supplementary Table I. We also identified whether companies had a specific "tagline", defined as a short statement embedded and/or closely linked to the company name/logo. The search was performed between March and July 2019, and data were checked a second time in December 2019. Data extraction was performed by authors (FGC, GZ) independently, and disagreements were resolved by discussion.

We clustered words used in vision, mission and payoff statements in four broad domains/themes:

a) Innovation and R\&D (i.e. words such as "innovative", "leading", "discover", "develop", etc.)

b) Impact on patient's life (i.e. words such as "patients", "people", "life", "care", etc.) c) Operational excellence (i.e. words such as "quality", "trust", "history", etc.)

d) Breadth of reach and access to drugs (i.e. words such as "world", "worldwide", "commercialization", "access", "affordable", etc.)

Standard descriptive analyses were performed on number and frequency of words reported in company values. Whenever words with a similar meaning (i.e. agility and simplicity) were listed together they were counted as one in the quantitative analysis. With reference to comparison between groups, categorical data were analysed using the contingency table analysis with the chi-square or Fisher's exact test, as appropriate, whereas continuous data were analysed using a Student's t-test, after checking whether data were normally distributed (based on the Shapiro-Wilk statistic, or a Wilcoxon rank-sum test otherwise. All tests were two-sided and a $p$ value of less than 0.05 was considered statistically significant. Data analyses were conducted using SAS version 9.4 (SAS Institute, Cary, NC, USA) statistical software.

Finally, two overall word cloud analyses were performed using the freely available TagCloud (tagcloud.com) app on the internet, which is considered the most appropriate when "strict, clear measurement is more important than aesthetics" (5). The first word cloud included all words appearing in mission, vision and tagline, the second included all words appearing in company value statements.

\section{Results}

Out of the top 50 global companies included in the rankingthebrand website (4), Shire was acquired by Takeda in the meantime and since its website reflected this change, it was not included in the present analysis.

Table I shows the taglines of the top global companies (31 out of 49 ): $42 \%$ of these pharma companies have tagline either embedded in their logo or very prominently listed on the header and/or landing page of the company website. In most cases we were able to identify what appeared to be mission $(90.7 \%)$ and vision (54.6\%) company statements. Out of the 49 companies, 36 (73.4\%) had values. Mean number of values was $4.9 \pm 1.7$ SD, median 4 , range from 2 to 10 .

Company values for the top 50 global companies are shown in Supplementary Table II.

TABLE I - Taglines consistently present on the company website of top 50 global companies. Updated to December 2019.

\begin{tabular}{lll}
\hline Company & Country HQ & Tagline \\
\hline Abbvie & US & People. Passion. Possibilities. \\
Actelion & Switzerland & Committed to PAH - today and tomorrow \\
Allergan & US & Live boldly \\
Aspen Pharmacare & South Africa & Healthcare. We care. \\
AstraZeneca & UK & We believe in what science can do \\
Bayer & Germany & Science for a better life \\
Biogen & US & Pioneers in neuroscience \\
Boehringer Ingelheim & Germany & Value through innovation \\
\hline
\end{tabular}


TABLE I - (Continued)

\begin{tabular}{|c|c|c|}
\hline Company & Country HQ & Tagline \\
\hline Celgene & US & Committed to improving the lives of patients worldwide \\
\hline Chugai & Japan & innovation all for the patients \\
\hline CSL & US & Biotherapies for life \\
\hline Daiichi Sankyo & Japan & Passion for innovation. Compassion for patients \\
\hline Danippon Sunimoto & Japan & Innovation today, healthier tomorrows \\
\hline Eisai & Japan & The human healthcare \\
\hline Endo Health Pharma & Ireland & Delivering quality medicines, helping patients in need \\
\hline Ferring & Switzerland & Helping mothers and babies, from conception to birth \\
\hline Fresenius & Germany & Forward thinking healthcare \\
\hline Mallinckrodt Pharma & UK & Managing complexity. Improving lives \\
\hline Merck KGaA & Germany & Vibrant science and technology \\
\hline Merck \& Co & US & Inventing for life \\
\hline Mylan & US & Better health for a better world \\
\hline Novartis & Switzerland & At Novartis, we are reimagining medicine \\
\hline Novo Nordisk & Denmark & Driving change, together \\
\hline Ono & Japan & Dedicated to man's fight against disease and pain \\
\hline Otsuka & Japan & People creating new products for better health worldwide \\
\hline Pfizer & US & Breakthroughs that change patients' lives \\
\hline Regeneron & US & Delivering life-transforming medicines \\
\hline Roche & Switzerland & Doing now what patients need next \\
\hline Sanofi & France & Empowering life \\
\hline Takeda & Japan & Better health, brighter future \\
\hline UCB & Belgium & Inspired by patients. Driven by science. \\
\hline
\end{tabular}

- Shire excluded from the analysis; Taglines linked to company logo are in bold.

TABLE II - Taglines consistently present on the company website of the convenience sample of selected companies

\begin{tabular}{lll}
\hline Name & Country HD & Tagline \\
\hline Alfasigma & Italy & Pharmaceuticals with passion \\
Almirall & Spain & Feel the science \\
Angelini & Italy & In the future since $\mathbf{1 9 1 9}$ \\
Baxter & US & At the intersection of saving and sustaining lives \\
Bial & Portugal & Keeping life in mind \\
Biocodex & France & Healthcare with passion and conviction \\
Bracco & Italy & Life from inside \\
Cantabria Labs & Spain & Celebrate life \\
Chiesi & Italy & People and ideas for innovation in healthcare \\
Esteve & Spain & Advancing health together \\
Expanscience & France & Protecting your health through innovation \\
Faes Labs & Spain & A lifetime taking care of your health \\
Ferrer & Spain & At the cutting edge, across the health spectrum, all over the world \\
Gedeon Richter & Hungary & Health is our mission \\
Genevrier & France & Your health is our priority \\
Grunenthal & Germany & Think innovation. Feel life. \\
\hline
\end{tabular}


TABLE II - (Continued)

\begin{tabular}{|c|c|c|}
\hline Name & Country HD & Tagline \\
\hline Helsinn & Switzerland & Building quality cancer care together \\
\hline Incyte & US & Pivotal. Science. \\
\hline Ipsen & France & Innovation for patient care \\
\hline Italfarmaco & Italy & Research, innovation, productive technology and international expansion \\
\hline JazzPharma & Ireland & Life-changing medicines. Redefining possibilities. \\
\hline Leo & Denmark & Dermatology beyond the skin \\
\hline Mayoly Spindler & France & Committed to your health. Every day. \\
\hline MedexusPharma & US & Enhancing treatment options for patients \\
\hline Mediolanum & Italy & Innovation and research since 1972 \\
\hline Merz & Germany & Live better. Feel better. Look better. \\
\hline Mundipharma & UK & To move medicine forward \\
\hline Rovi & Spain & Researching to grow for health \\
\hline Santen & Japan & A clear vison for life \\
\hline Santhera & Switzerland & Their future-our focus \\
\hline Sobi & Sweden & Rare strength \\
\hline Thea & France & Let's open our eyes \\
\hline Zambon & Italy & Life enhanced \\
\hline
\end{tabular}

Table II illustrates the taglines for the convenience sample of smaller companies selected for our study. Out of the 48 companies analysed, 33 (68.7\%) listed values. Mean number of values $5.3 \pm 1.9 \mathrm{SD}$, median value 4 , range 3 to 10 . Company values for the smaller companies are shown in Supplementary Table III.
To have a holistic view of the most frequent words used by pharma in their mission, vision and taglines, we combined the statements from the entire set of companies and performed an overall word cloud of all the names, attributes and verbs used in those statements. Figure 1 illustrates the TagCloud of the top 100 words used in company statement.

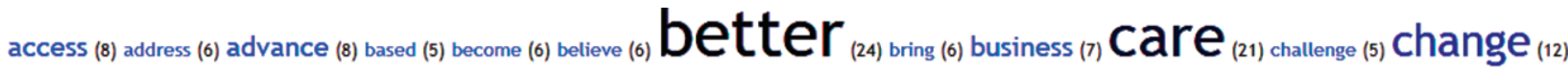

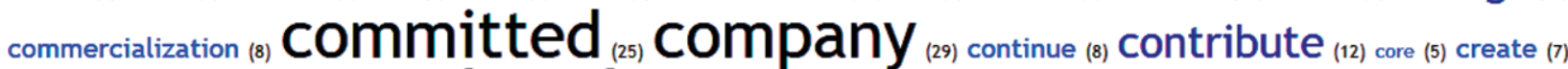
dedicated (ind deliver ind development driving (8) drugs (8) effective (6) enhance (6) families (6) feel (7) foCUS (11) fOCUSed (11) full (5) future (11) glObal (18) goal (5) group (5) health ${ }_{(3)}$ healthcare ${ }_{(20)}$ healthy ${ }_{(0)}$ help ${ }_{(2)}$ human $_{(2)}$ improve

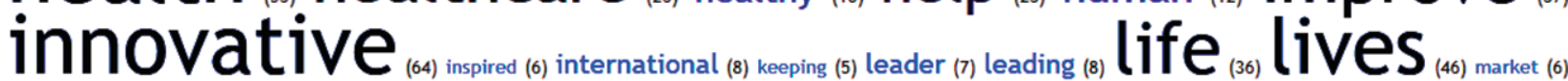

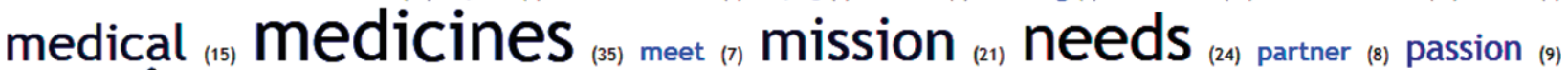

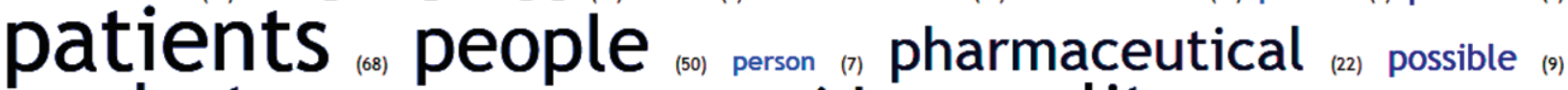

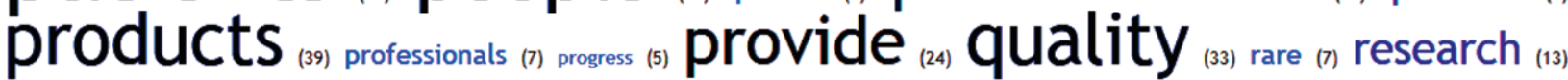

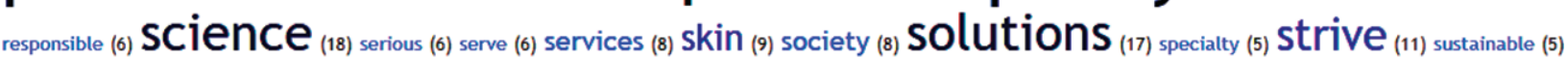

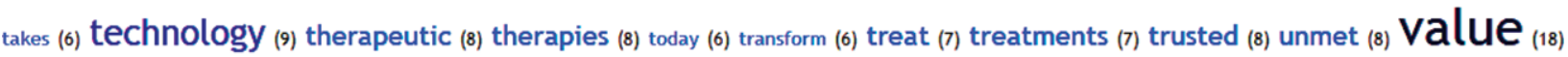
vision (11) well-being (r) work (10) World $\mathbf{d}_{(3)}$ worldwide (10) years (n)

Fig. 1 - Word cloud of top 100 words listed within vision, mission and tagline of pharma companies. 
accountability (9) acting (3) adaptable (2) agility (3) appreciate (2) approach (2) audacity (2) business (4) caring (7) centred (2) citizenship (2) collaboration (10) commitment (8) community (6) competitiveness (3)

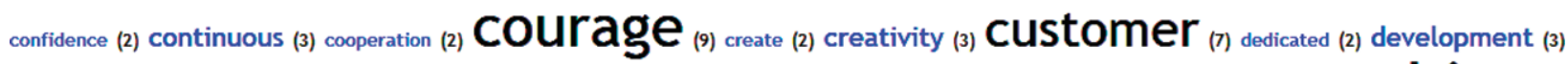
diversity (4) driven (4) efficiency (3) entrepreneurial (2) entrepreneurship (2) environment (2) environmental (4) ethics $_{(14)}$ excellence (2) oxpert (2) flexible (1) focus

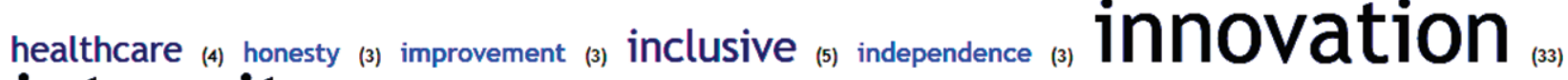
(11) future (2) generation (2) global (2) growth (2) harmony (3)

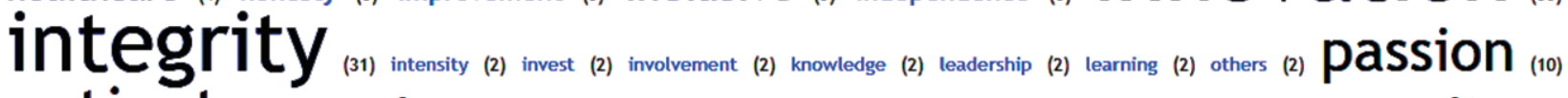

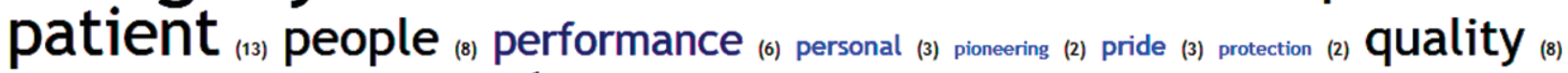

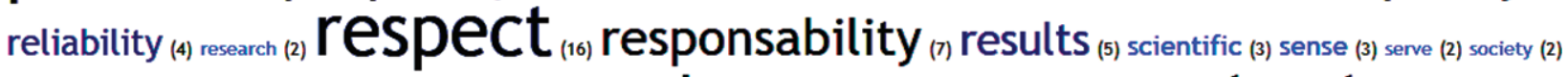

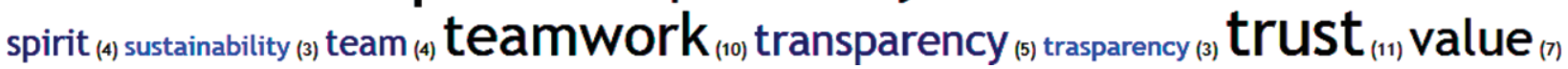

Fig. 2 - Word cloud of words listed at least twice among company values.

The words "life/lives" were the most frequent reported, followed by "patients", "innovative", "people/persons".

Similarly, to have a holistic view of the most frequent values mentioned in pharma corporate statements, we performed an overall word cloud of all the values mentioned. Figure 2 illustrates all the words appearing at least twice within company values. The words "innovation" and "integrity" were by far the most common values, followed by "respect", "ethics", "responsibility" and "passion".

A further, in-depth quantitative analysis of the dataset indicated that the themes and concepts associated with patient health, quality of life and their engagement and empowerment were most common, since $89.7 \%$ of companies referred to those themes. Similarly frequent was the broad theme of innovation ( $80.4 \%$ of companies). On the other hand, reference to themes related to operational excellence and trust and/or access to drugs was significantly less frequent, being discernible in approximately half of the cases $(51.6 \%$ and $49.5 \%$ respectively).

Lastly, we looked to see whether the sizes of the companies or the geographical location of their HQ could have some influence on the type and focus of the words used (Tab. III).

TABLE III - Number of companies with vision and mission and number of values by company size and company HQ location.

\begin{tabular}{|c|c|c|c|c|c|c|c|c|c|}
\hline & \multicolumn{4}{|c|}{ Company size } & \multicolumn{5}{|c|}{ Company HQ location } \\
\hline & $\begin{array}{c}\text { All } \\
\text { companies }\end{array}$ & Top 50 & Other & $\begin{array}{c}\mathrm{P} \text { for } \\
\text { comparison }\end{array}$ & $\begin{array}{l}\text { USA/ } \\
\text { Canada }\end{array}$ & $\begin{array}{l}\text { Europe/ } \\
\text { Israel }\end{array}$ & Japan & Other & $\begin{array}{c}P \text { for } \\
\text { comparison }\end{array}$ \\
\hline No with vision (\%) & $53(54.6)$ & $33(67.4)$ & $20(41.7)$ & 0.01 & $11(47.8)$ & $29(49.1)$ & $10(83.3)$ & $3(100.0)$ & 0.08 \\
\hline No with mission (\%) & $88(90.7)$ & $45(91.8)$ & $43(89.6)$ & 0.74 & $22(95.6)$ & $53(89.8)$ & $12(100.0)$ & $1(33.3)$ & 0.38 \\
\hline $\begin{array}{l}\text { No company values } \\
\text { (Mean } \pm \text { SD) }\end{array}$ & $3.7 \pm 2.8$ & $3.8 \pm 2.5$ & $3.7 \pm 3.0$ & 0.97 & $3.1 \pm 2.8$ & $4.1 \pm 2.8$ & $3.3 \pm 2.5$ & $3.3 \pm 2.9$ & 0.43 \\
\hline $\begin{array}{l}\text { Median no of company } \\
\text { values }\end{array}$ & 4 & 4 & 4 & & 4 & 4 & 3.5 & 5 & \\
\hline
\end{tabular}

Note: Comparisons were performed between USA/Canada, Europe/Israel and Japan.

The only significant difference was that larger companies seem to include a vision statement more often than smaller companies (67.4\% vs. $41.7 \%, p=0.01)$. For what concerns the geographical location, although some trends were noticeable, there was no clear indication that this per se plays any relevant role, although Japanese companies seem particularly meticulous in indicating a mission (100\%) and a vision (83.3\%) on their company websites.

\section{Discussion}

The main purpose of the pharmaceutical industry is to bring to market drugs and devices that help humans to prevent the occurrence of disease and help patients with acute or chronic diseases to live longer lives and/or experience a better quality of life. A very large number of people are employed by pharma companies and therefore the choice of 
words in company statements has a direct influence on several million workers worldwide. These two concepts were clearly present in a recent post by lan Read, Pfizer chairman, in which he stated "The purpose of the pharmaceutical industry is to bring patients innovative new therapies that help them to live longer, healthier lives. That is our reason for existing and is the reason that millions of people come to work for the pharmaceutical industry each day" (6).

Several authors have analysed the content of a mission statement of companies, usually by focussing on specific country such as the United States (7), using parameters such as existential purpose, fundamental values, social responsibility, literary composition and semantic impact, or Italy (8) using the model developed by David (9).

However, the literature on mission, vision and values of pharma companies is relatively scanty $(10,11)$. To the best of our knowledge, this is the first in-depth analysis performed to collect and cluster the words used by multinational pharma companies when articulating their company statements.

A first analysis of our dataset suggests the possibility to cluster the words into four broad themes/concepts: (1) R\&D and Innovation; (2) Value for Patients; (3) Operational Excellence and Trust; (4) Access to Treatment. Not surprisingly, the first two themes were present in the vast majority of company statements (four out of five companies would list either of them), whereas the latter themes were emphasized in only half of company statements. Among company mission and vision statements, "life/lives", "patients", "innovative", "people/persons" were mentioned at least 50 times. On the other hand, words referring to other major healthcare stakeholders appeared very rarely: "professionals" was listed seven times, there was only one mention to "physicians/doctors" and none to "nurses", "pharmacists" and "payors". Of note, we did not find any comparative statements (i.e. we are better/ larger than our competitors). In fact, when we first started the dataset analysis, we identified one company, Mundipharma, whose tagline was very strongly focussed on competitors and read "we see what others don't". However, the statement was recently changed to a simpler, less ambitious, noncomparative statement: "to move medicine forward".

The lack of focus on the theme of economic and environmental sustainability was somewhat surprising: the term "sustainable" was present only five times and the term "environment" was not used anywhere.

Analysis of the word cloud of the company values indicates that "innovation" and "integrity" are by far the most commonly used words, either of them used in 30 instances or more, with "respect", "ethics", "responsibility", "patient", "passion" and "team-teamwork" all mentioned in more than 10 instances. It is clear that there is a strong focus towards inward-looking company values while value for the patient, or more generally, the consumer, is somewhat lacking. Overall, the term "innovation" thus emerges as the most quoted word in company statements. On the other hand, words such as "sustainability", "transparency" and "environment(al)" were rarely mentioned among company values. We expect this to evolve significantly within the next few months/years as sustainable business models, open science, general transparency in business and care for the environment become even more critical for building a strong company reputation on the web.

\section{Implication for reputation of pharma companies}

Building a strong reputation with patients and consumers is a difficult challenge for companies worldwide. According to studies by the Reputation Institute, no pharma company ranks among the Top 10 companies globally, and their rank is average both in the United States (1) and in France (2). Pharma companies still suffer from some of the lowest familiarity levels across industries and, on the other hand, face a wide variety of reputational challenges, including the increased public and regulatory scrutiny of unaffordable drug costs for new innovative therapies. Their perceived focus on profit vs. societal benefits dents their effort to establish a strong positive reputation. Our analysis suggests that there are still significant areas of improvement in corporate pharma communications. First, not all the companies have a clear tagline that is easy to articulate; second, it is sometimes difficult to dissect their vision and mission or purpose. Third, company values tend to be very much "inward" rather than "outward" looking so that value for their customers is sometimes overlooked. Finally, broader topics such as transparency, economic sustainability and care for the environment are infrequently listed as core company values, indicating that companies are still very much focussed on their core competences and business.

\section{Limitations of our study}

A few important limitations of the study must be mentioned. First, the distinction between mission and vision on some of the websites was not straightforward. In other cases, values were not clearly mentioned on the website but were later identified in company brochures or other material. It is therefore possible that in some cases values are not missing as currently indicated in Supplementary tables II and III.

Second, the companies to be analysed were selected based on a combination of quantitative data (ranking of companies worldwide) and the expert advice of professionals working with these companies in different countries. This advice is by definition based on a somewhat subjective judgement but we felt it was the best approach to have a representative selection of companies under scrutiny.

Third, we did not embark into analysing Chinese $\mathrm{HQ}$ pharma companies, since their presence in the major US and European countries is still relatively modest, but we acknowledge that their role will become much more relevant in the next 3 to 5 years and we plan to run specific analyses on them.

\section{Conclusions}

This dataset represents a baseline reference that can be useful to follow the evolution in the company communication messages, in light of the rapid changes from an M\&A, business and scenario perspective.

The results of our analysis indicate that most multinational pharma companies provide comprehensive statements, focussing their vision and mission statements mostly on their innovative R\&D approach and their impact on patient prognosis and their quality of life. 
However, an in depth analysis of their alignment with key needs and trending topics is warranted to further engage their customers in order to build their reputation index and ultimately their value within the business community.

\section{Acknowledgements}

The authors are grateful to the following individuals for identifying companies included in our analysis: Christopher Basset (UK), Juan de La Fuente (Spain and Portugal), Thierry Henane (France), Fabian Kaufmann (Germany).

The authors are also thankful to Eric Merkel Sobotta and Maurizio De Cicco for reviewing the manuscript and sharing very helpful comments.

\section{Disclosures}

Financial support: The authors declare no financial support. Conflict of interest: The authors have no financial disclosures to declare.

\section{References}

1. Klingemann S. Understanding the state of the U.S. Pharma Industry in 2019. https://insights.reputationinstitute.com/ healthcare-pharma/2019-pharma-research-summary.

Accessed February 27, 2020.
2. Ostrowski M. 2019 France Pharma Rep Track. https://insights. reputationinstitute.com/homepage/2019-france-pharmareptrak. Accessed February 27, 2020.

3. Mirvis P, Googins B, Kinnicutt S. Vision, mission, values: guideposts to sustainability. Organ Dyn. 2010;39(4):316-324.

4. Ranking the brands Top 100. https://www.rankingthebrands.com/ The-Brand-Rankings.aspx?rankingID=370. Accessed February 27, 2019.

5. Poll everywhere. https://blog.polleverywhere.com/best-wordcloud-generator/. Accessed February 27, 2020.

6. Why society needs a vibrant pharmaceutical industry: improving patients' lives. https://www.linkedin.com/pulse/ 20140612143605-322581966-why-society-needs-a-vibrantpharmaceutical-industry-improving-patients-lives/. Accessed February 27, 2020.

7. Brătianu C, Bălănescu GV. Vision, mission and corporate values. A comparative analysis of the top 50 U.S. companies. Manage Marketing. 2008;3(3):19-38.

8. D'Amato V, Tosca E, Macchi F. Web based mission statements in top Italian companies. World J Manage. 2017;8:18-34.

9. David FR. How companies define their mission. Long Range Plann. 1989;22(1):90-97.

10. Azisi S, Hosseinabadi V. Content analysis of the mission statements of Iran, Turkey, India and United States pharmaceutical companies. Manage Marketing J. 2014;12(1):52-66.

11. Arefin S, Md. Rajib SU, Bhuiyan YA. Mission statements of pharmaceutical firms in Bangladesh: missing link and probable impact. J Innovat Sustain. 2011;2(3):52-58. 